University of Nebraska - Lincoln

DigitalCommons@University of Nebraska - Lincoln

Papers in Biomaterials

Chemical and Biomolecular Engineering

Research and Publications

October 1998

\title{
Enzymatic Glycerolysis of Soybean Oil
}

Hossein Noureddini

Department of Chemical Engineering, University of Nebraska-Lincoln, hnouredd@unlnotes.unl.edu

S E. Harmeier

Department of Chemical Engineering, University of Nebraska-Lincoln

Follow this and additional works at: https://digitalcommons.unl.edu/chemeng_biomaterials

Part of the Biomaterials Commons

Noureddini, Hossein and Harmeier, S E., "Enzymatic Glycerolysis of Soybean Oil " (1998). Papers in Biomaterials. 9.

https://digitalcommons.unl.edu/chemeng_biomaterials/9

This Article is brought to you for free and open access by the Chemical and Biomolecular Engineering Research and Publications at DigitalCommons@University of Nebraska - Lincoln. It has been accepted for inclusion in Papers in Biomaterials by an authorized administrator of DigitalCommons@University of Nebraska - Lincoln. 


\title{
Enzymatic Glycerolysis of Soybean Oil
}

\author{
H. Noureddini* and S.E. Harmeier \\ Department of Chemicai Engineering, University of Nebraska-Lincoln, Lincoln, Nebraska 68588-0126
}

\begin{abstract}
Enzymatic glycerolysis of soybean oil was studied. Of the nine lipases that were tested in the initial screening, Pseudomonas $\mathrm{sp}$. resulted in the highest yield of monoglycerides. Lipase from Pseudomonas sp. was further studied for the influence of temperature, thermal stability, enzymefoil ratio, and glycerol/oil ratio. A full factorial optimization approach was performed. The following conditions were tested over the specified ranges: temperature $\left(30-70^{\circ} \mathrm{C}\right)$, thermal stability $\left(30-70^{\circ} \mathrm{C}\right)$, enzyme/oil ratio $(0.05-0.2 \mathrm{~g}$ enzyme/ $10 \mathrm{~g}$ oil), glycerol/oil ratio (1:1-3:1 glycerol/oil molar ratio) and $1 \mathrm{~h}$ reaction time. The stability of the enzyme at the reaction temperature was also incorporated as a separate variable. At temperatures above $40^{\circ} \mathrm{C}$ enzyme denaturation offset the higher activity. The optimal conditions were selected to be the basis for a continuous process: $40^{\circ} \mathrm{C}$, a glycerolioil molar ratio of $2: 1$, and an enzyme/oil ratio of $0.1 \mathrm{~g}$ enzyme $/ 10 \mathrm{~g}$ oil. A definition for glycerolysis activity was adopted. The glycerolysis activity (1 GU) was defined as the amount of enzyme necessary to consume 1 $\mu \mathrm{mol}$ of substrate (glycerol and oil) per minute. This research is intended to explore the reaction parameters that are important in a continuous enzymatic glycerolysis process.
\end{abstract}

JAOCS 7S, 1359-1365 (1998).

KEY WORDS: Diglycerides, enzyme, glycerol, glycerolysis, monoglycerides, soybean oil, triglycerides.

The conversion of fats and oils into value-added products such as fatty acids (FA) and their derivatives has been of major commercial interest. The physiochemical synthesis of these products is a well-established industrial process. These processes normally involve an inorganic homogeneous catalyst and high temperatures and pressures. For example, a mixture of monoglycerides (MG) and diglycerides (DG) is commercially manufactured by the glycerolysis reaction, in which fats and oils undergo a transesterification reaction with glycerol. This is a physiochemical process and requires high temperatures $\left(220-260^{\circ} \mathrm{C}\right)$ and use of an inorganic homogeneous catalyst. such as sodium, potassium, or calcium hydroxide (1-3). MG and DG have also been prepared by direct esterification of FA or their alkyl esters with glycerol. Much like the previous example, the reaction temperature is above $200^{\circ} \mathrm{C}$ and inorganic homogeneous catalysts are required $(4-6)$. The established industrial process for the hydrolysis of triglycerides (TG) is the Colgate-Emery method, which is carried out at $250^{\circ} \mathrm{C}$ and 50

*To whom correspondence should be addressed. E-maii: hnoureddini@unl.edu atm (7). Both hydrolysis and glycerolysis processes are highly energy intensive and require high capital investments. Furthermore, severe conditions for temperature and pressure result in side reactions, and further purification of the final product is normally required ( 8 ). The positive side of these reactions is high conversions and relatively short reaction times.

Enzymatic glycerolysis of fats and oils at atmospheric pressure at nearly ambient temperatures has been investigaied as an alternative method for the conventional chemical methods used for the industrial production of MG and DG. Obviously, operation under ambient conditions would require a lower capital investment. Research findings in recent years have also revealed other advantages of enzymatic processes. Owing to the specificity of enzymes, negligible amounts of undesired products are obtained, and for many applications no purification of products is required. Moreover, mild reaction conditions make enzymatic reactions suitable for heatsensitive glycerides.

Optimization of the reaction conditions for the glycerolysis of fats and oils in a batch-wise setting has been the topic of many studies. In particular, temperature, glycerol/TG molar ratio, enzyme/oil mass ratio, and water concentration are the major reaction variables. McNeil and co-workers $(8,9)$ used lipase from Pseudomonas fluorescens in the glycerolysis of beef tallow and palm oil. The reaction was allowed to proceed until equilibrium was reached. A critical temperature was defined as the temperature below which a large increase in MG formation was observed. It was concluded that at this temperature the $\mathrm{MG}$ crystallized from the reaction mixture, driving the reaction further. In the range $38-46^{\circ} \mathrm{C} .70 \% \mathrm{MG}$ was obtained. while from $48-50^{\circ} \mathrm{C}, 30 \% \mathrm{MG}$ was obtained. of the eight commercially available enzymes that were tested, lipase from Chromobacterium viscosum and P. f7uorescens produced the highest yield. Cao et al. (10) obtained $63 \%$ MG from olive oil using lipase from Pseudomonas sp. The highest yield was obtained at $38^{\circ} \mathrm{C}$ due to MG crystallization. The reaction was allowed to proceed for several hours until equilibrium was reached. An optimum glycerol/oil molar ratio of 2:1 was obtained. Holmberg et al. (1 I) used aqueous and nonaqueous microemulsions in the glycerolysis and hydrolysis of palm oil using a 1,3-specific lipase and sodium bis(2-methylhexyl)sulfosuccinate as surfactant. Presence of even a small amount of water showed a substantial increase in the rate of glycerolysis. The molar ratio of water and glycerol to surfactant of 3.4 resulted in optimal MG yield. 
Hoq er al. (12) used lipase from C. riscosim to form giycerides from glycerol and FA. The glycerol contained 3-4 wi $\%$ water and 1 wt $\% \mathrm{CaCl}_{2}$. The reaction temperature was $40^{\circ} \mathrm{C}$. Conversion increased linearly with lipase concentrations from $0-20 \mathrm{mg} / \mathrm{g}$ glycerol. No further increase was observed at concentrations greater than $20 \mathrm{mg} / \mathrm{g}$ glycerol. Enzyme half-life was $52 \mathrm{~d}$ in the presence of $\mathrm{Ca}^{2+}$ and $21 \mathrm{~d}$ in its absence. Daeseok and Rhee (13) examined the effects of various ions on lipase from Candida nigosa. They found that $\mathrm{Ca}^{3+}, \mathrm{Co}^{2+}$, and $\mathrm{Mg}^{2+}$ inhibited the reaction, while $\mathrm{Fe}^{3+}, \mathrm{Cu}^{2+}$, and $\mathrm{Hg}^{2+}$ were toxic. Histidine and other amino acids protected against small amounts of $\mathrm{Cu}^{2+}$. The inhibitory effect of $\mathrm{Ca}^{2+}$ is contradictory to the above work, which reported enzyme stabilization in the presence of $\mathrm{Ca}^{2+}$.

As with any new process, the driving force behind the enzymatic process is a lower production cost. Lipases have the potential to lower this cost in three ways: (i) lower process temperature decreases the energy input, (ii) no by-products are formed, eliminating the need for a purification process, and (iii) through immobilization, the catalyst can be used many times before replacement. In contrast, certain disadvantages also exist. In particular, slower reaction rates and high enzyme cost must be overcome to make the process feasible.

The aim of this present work is to explore the reaction parameters for the enzymatic glycerolysis of soybean oil. Results discussed in this paper include enzyme screening. the effect of the molar ratio of glycerol and oil, enzyme louding, residual enzyme activities, and reaction time and temperature. The results of this research will lay the foundation for a continuous enzymatic glycerolysis setting to alleviate some of the disadvantages that exist.

Glycerolysis activity. For comparison of enzyme reactions, activities are defined. The International Commission on Enzymes defines one International Unit of enzyme as the amount that catalyzes the formation of $1 \mu \mathrm{mol}$ of product in 1 $\min (14)$. Therefore, in lipase-catalyzed hydrolysis, one unit is that amount of enzyme required to liberate $1 \mu \mathrm{mol}$ of FA per min. The reactions are done over some period of time, and the average product formation per minute is determined. However, when dealing with glycerolysis reactions, this hydrolytic activity has little meaning (15). Many times, lipases are compared in glycerolysis reactions on the basis of hydrolytic activity. For example, the units of lipase added to a reaction will be kept constant. In these cases, the mass of enzyme added to the reaction will depend on the hydrolytic activity. Since the hydrolytic activity does not accurately reflect the glycerolysis activity, the lipase comparison means nothing. A glycerolysis activity should be defined for lipase comparison in glycerolysis reactions.

A definition of glycerolysis activity is not as forthcoming as the definition of hydrolytic activity. In hydrolysis, FA are the desired product. Therefore, the activity definition reflects the accumulation of desired products. In glycerolysis, MG is the desired product. However, an activity definition that focuses on MG production does not accurately describe enzymaic activity. Two MG can be produced when a glycerol molecule reacts with a TG. Alternatively, the enzyme is equally active when an MG molecule reacts with a TG to produce two DG.

A useful definition of glycerolysis activity can still come from the definition of hydrolysis activity, however. In hydrolysis, the enzyme is active whenever an FA is released. This event also corresponds to the consumption of a water molecule. Therefore, hydrolytic activity can be defined in terms of the FA formation or water consumption. In glycerolysis, the lipase is active when either a glycerol or a TG molecule is consumed. Glycerol can be consumed without consuming TC by the formation of Iwo MG from a DG. Likewise, TG can be consumed without consuming glycerol by the formation of two DG from an MG and TG. Thus. the following definition of glycerolysis activity will be used: $1 \mathrm{GU}=$ the amount of enzyme necessary to consume $1 \mu \mathrm{mol}$ of substrate (glycerol and oil $/$ min over $1 \mathrm{~h}$. This definition is still consistent with the International Commission on Enzymes definition. The only difference is that the glycerolysis activity measures substrate consumed instead of product formed.

\section{EXPERIMENTAL PROCEDURES}

Materials. Bleached and refined soybean oil was provided by the Archer Daniels Midland Co. (Lincoln, NE). Glycerol (99.9\%) was purchased from Sigma Chemical Company (St Louis, MO). Distilled water was mixed with the glycerol. AI enzymes were generously donated by Amano Enzyme Company (Lombard, IL). High-performance liquid chromatography (HPLC)-grade acetone and acetonitrile and all standards for HPLC analysis were purchased from Sigma Chemical Company.

Procedures. For lipase screening, a standard set of conditions was adopted: $2: 1$ glycerol/oil molar ratio, $0.1 \mathrm{~g}$ enzyme/ $10 \mathrm{~g}$ oil, $40^{\circ} \mathrm{C}$, and $1 \mathrm{~h}$ reaction time. The glycerol/oil ratio is the stoichiometric ratio for complete conversion to $\mathrm{MG}$. The reactions were run in a water bath under which a Thermolyne (Dubuque, IA) Mirak 4-place magnetic stirrer model \#S73135 was placed to agitate the reaction mixture. Water was circulated into the bath from a Neslab (Portsmouth, NH) RTE-211 Bath/Circulator which, via an external probe, was able to control the temperature to within $\pm 0.01^{\circ} \mathrm{C}$. Reactions were run in 50-mL Erlenmeyer flasks with rubber stoppers.

In preparation for a reaction, $0.1 \mathrm{~g}$ lipase was placed into the flask, followed by the addition of $10 \mathrm{~g}$ soybean oil. This mixture was stirred for a few seconds to thoroughly disperse the enzyme in the oil. Finally, $2.18 \mathrm{~g}$ glycerol/water was added. The glycerol/water solution was $3.5 \mathrm{wt} \%$ water, making the amount of glycerol added equal to the desired 2:1 molar ratio with respect to soybean oil. The reaction mixture was then placed in the water bath and stirred at $700 \mathrm{rpm}$ for 1 h. Nine lipases, as listed in Table 1, were screened for glycerolysis activity.

Batch reaction optimizarion. Lipase from Pseldomonas sp. was selected to further study the influence of temperature, thermal stability, enzyme/oil ratio, and glycerol/oil ratio. A 
TABLE 1

Lipases Tested in Clycerolysis Screening

\begin{tabular}{cl}
\hline Lipase & Source organism \\
\hline R & Penicillium roqueforti \\
AK & Pseudomonas sp. \\
PS & Pseudomonas sp. \\
M & Mucor sp. \\
A & Aspergillus niger \\
FAP & Rhizopus oryzae \\
G & Penicillium camembertii \\
N & Rhizopus niveus \\
AY & Candida rugosa \\
\hline
\end{tabular}

full factorial optimization approach was performed. The following range of conditions was tested: temperature $\left(30-70^{\circ} \mathrm{C}\right)$, thermal stability $\left(30-70^{\circ} \mathrm{C}\right)$, enzyme/oil ratio $(0.05-0.2 \mathrm{~g}$ enzyme $/ 10 \mathrm{~g}$ oil), and glycerol/oil ratio (1:1-3:1 glycerol/ oil molar ratio). While the variations in one parameter were being tested, the other parameters were maintained at the baseline conditions. The baseline conditions were the same as what was outlined earlier for the enzyme screening procedures. It has been shown that little interaction exists between these critical parameters during the course of glycerolysis process (16). The reaction procedures were carried out in the same manner as in lipase screening.

Thermal stability was tested by incubating the lipase and oil at the reaction temperature for $1 \mathrm{~h}$ followed by glycerol addition and reaction for another $h$. By comparing the reaction results with those from the normal temperature test, lipase denaturation was examined.

Sampling and analysis. HPLC was used to analyze reaction products. In this analysis scheme, $M G, D G$, and $T G$ could be separated. At the end of the reaction, the reaction mixture consisted of glycerol/water, MG, DG, TG, lipase, and a small amount of $F A$. The total amount of $M G, D G$, and $T G$ was identified in the analysis.

Samples were drawn at the end of the each run ( $1 \mathrm{~h}$ ). Sam. ples were collected in 8 -mL vials, filled with $5 \mathrm{~mL}$ of HPLC solvent $(50: 50 \mathrm{vol} / \mathrm{vol}$ acetone/acetonitrile), and approximately $60 \mathrm{mg}$ of the reaction mixture was sampled. The mixture was shaken vigorously. The solution was centrifuged and the supematant poured out to remove the insoluble enzyme.

The HPLC setup consisted of an ISCO (Lincoln, NE) model 2350 pump and a Thermo Separation Products (Riviera Beach, FL) refracto Monitor IV refractive index detector. Data collection and analysis were performed with HewlettPackard (Wilmington, DE) Chemstation Software. A Spherisorb OSD 2 column (Phase Separation Inc., Norwalk, CT), $250 \times 4.6 \mathrm{~mm}$ with $80 \AA$ pore size and $5 \mu \mathrm{m}$ particle size was used for the separation. The HPLC mobile phase consisted of a 50:50 volumetric mixture of acetone and acetonitrile. The mobile system was degassed for $20 \mathrm{~min}$ in an ultrasonic bath before use. The HPLC pump operated at 0.70 $\mathrm{mL} / \mathrm{min}$, and the column temperature was maintained at $35^{\circ} \mathrm{C}$. Standards for $\mathrm{MG}, \mathrm{DG}$, and TG were used to establish the calibration charts. In using these calibration charts, all of the integration results were corrected for the mole percentages of the individual components.

\section{RESULTS AND DISCUSSION}

Lipase screening. Lipases tested are listed in Table 1. Reaction products are presented as mol\% MG, DG, and TG in the glyceride portion of the reaction mixture. The mole percentage of MG, DG, and TG for each lipase is presented in Figure 1. This figure shows that lipase PS from Pseudomonas sp. resulted in the highest leve] of MG and DG, followed by lipase FAP from Rhizopus oryzae. All other lipases showed relatively low reaction rates. Lipase AK (also from a Pseudumonas sp.), while having low MG in the product, produced a relatively large amount of DG.

The extent of reaction is also reflected in Figure 2, which shows the glycerolysis activity, defined earlier as the amount of enzyme necessary to consume $1 \mu \mathrm{mol}$ of substrate (glycerol and oil)/min over $1 \mathrm{~h}$. Again, lipases PS and FAP showed much higher activities than the other enzymes.

Lipases are normally rated with a hydrolysis activity. The hydrolysis activities along with glycerolysis activities for the enzymes tested in our laboratory are listed in Table 2. Hydrolysis activities are from the manufacturer's listing. Lipase PS, which has a relatively low hydrolysis activity, has the highest glycerolysis activity. When hydrolysis and glycerolysis activities are compared, litcle correlation is seen. Therefore, judging a glycerolysis reaction based on hydrolytic activity will yield an inaccurate assessment.

Batch reaction optimization. A standard set of conditions which was adopted earlier for the enzyme screening experiment was used as the baseline in the optimization studies.

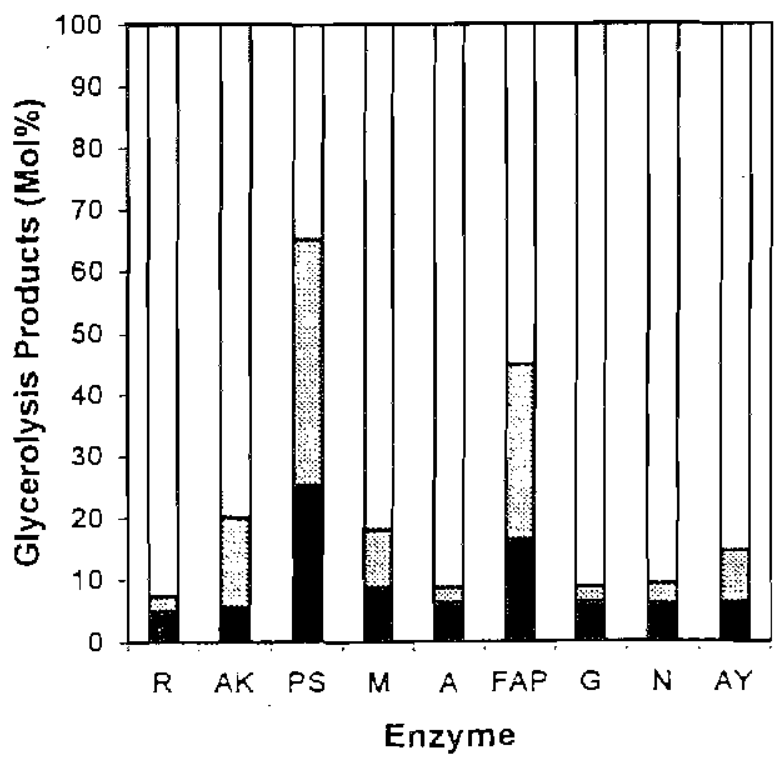

FIC. 1. Glycerolysis of soybean oil using variols lipases at $40^{\circ} \mathrm{C}$, a $2: 1$ molar ratio glycerol/oil, and $0.1 \mathrm{~g}$ enzyme/10 g oil. (ए) triglycerides; (5) diglycerides; (1) monoglycerides. See Table 1 for identification of enzyme sources. 


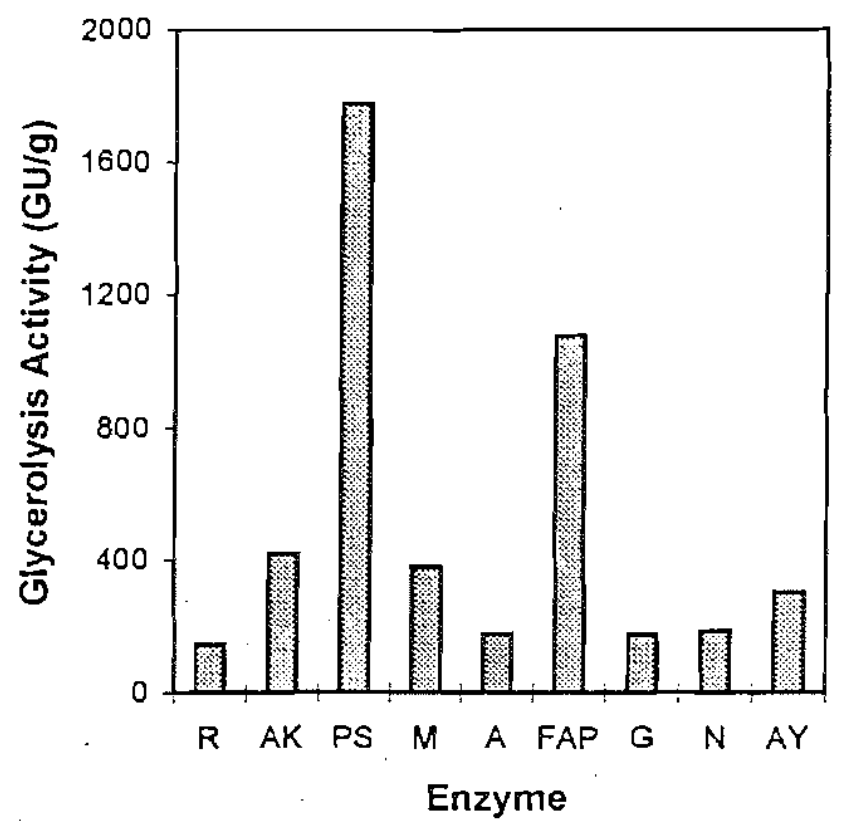

FIC. 2. Activity of screened lipases in soybean oil glycerolysis. See Table ? for enzyme sources.

Only one reaction parameter was varied at a time. For example, when the effect of temperature was investigated, the rest of the reaction conditions were maintained at: $2: 1$ glycerol/oil molar ratio, $0.1 \mathrm{~g}$ enzyme $/ 10 \mathrm{~g}$ oil, and I h reaction time. Lipase PS was used in all of the optimization studies.

Effect of temperature. Temperatures in the range of $30-70^{\circ} \mathrm{C}$ were tested at $5^{\circ} \mathrm{C}$ increments. The reaction products as a function of temperature for the glycerolysis of soybean oil with enzyme PS subject to $1 \mathrm{~h}$ of reaction time are presented in Figure 3. This figure shows that the greatest amount of $M G$ is produced at $55^{\circ} \mathrm{C}$. As the reaction temperature is increased, there is an increasing trend in the formation of products. This product formation reaches a maximum and starts to decrease as temperature is increased further. This is consistent with the expected loss in enzyme activity at elevated temperatures (above $55^{\circ} \mathrm{C}$ ) due to enzyme denaturation. The temperature dependency in the formation of products in

TABLE 2

Comparison of Clycerolysis and Hydrolytic Activities of Lipases

\begin{tabular}{lcccc}
\hline Lipased & $\begin{array}{c}\text { Glycerolysis } \\
\text { activity } \\
\text { (GU/g) }\end{array}$ & $\begin{array}{c}\text { Normalized } \\
\text { glycerolysis } \\
\text { activity }\end{array}$ & $\begin{array}{c}\text { Hydrolysis } \\
\text { activity } \\
\text { (U/g) }\end{array}$ & $\begin{array}{c}\text { Normalized } \\
\text { hydrolysis } \\
\text { activity }\end{array}$ \\
\hline R. & 147.0 & 0.08 & 1,040 & 0.01 \\
AK & 420.9 & 0.24 & 21,000 & 0.13 \\
PS & 1779.3 & 1.00 & 31,100 & 0.19 \\
M & 378.9 & 0.21 & 10,200 & 0.06 \\
A & 176.3 & 0.10 & 128,000 & 0.77 \\
FAP & 1078.3 & 0.61 & 167,000 & 1.00 \\
G & 178.0 & 0.10 & 53,500 & 0.32 \\
N & 186.8 & 0.10 & 92,800 & 0.56 \\
AY & 301.4 & 0.17 & 31,700 & 0.19 \\
\hline
\end{tabular}

Lipase sources are listed in Table 1.

${ }^{b_{1}} \mathrm{CU}=$ amount of enzyme necessary to consume ! prnol of substrate (glycerol and ail)/min over $1 \mathrm{~h}$.

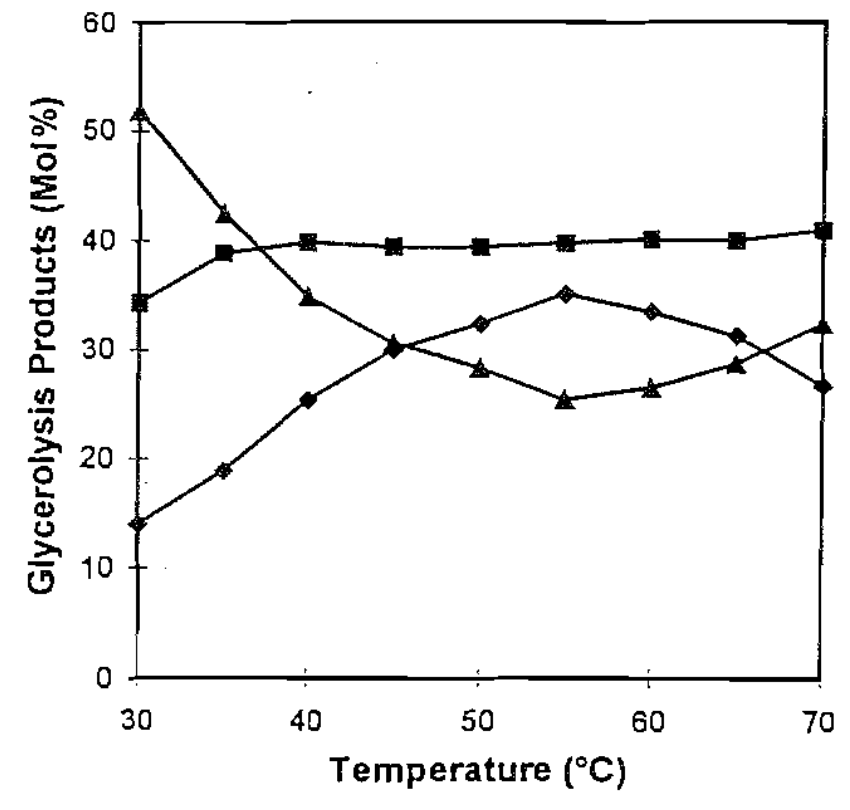

FIC. 3. Ef́fect of temperature on soybean oil glycerolysis at a $2: 1$ molar ratio giycerolioil and 0.1 g lipase PS/10 g oil. (\$) Monoglycerides; (-) diglycerides; $(\mathbb{A})$ triglycerides. Lipase PS, from Pseudomonas sp.

the glycerolysis reaction is also consistent with the glycerolysis activity, which can be seen in Figure 4.

Residual activity. Residual activity refers to testing the enzyme stability at various temperatures. The temperature at which the highest reaction yield is obtained after $1 \mathrm{~h}$ may not be the best temperature at which to operate a process. As well as increasing the reaction rate, elevated temperatures lead to more rapid enzyme denaturation. Since it is not economically feasible to be constantly replacing catalyst in process, a

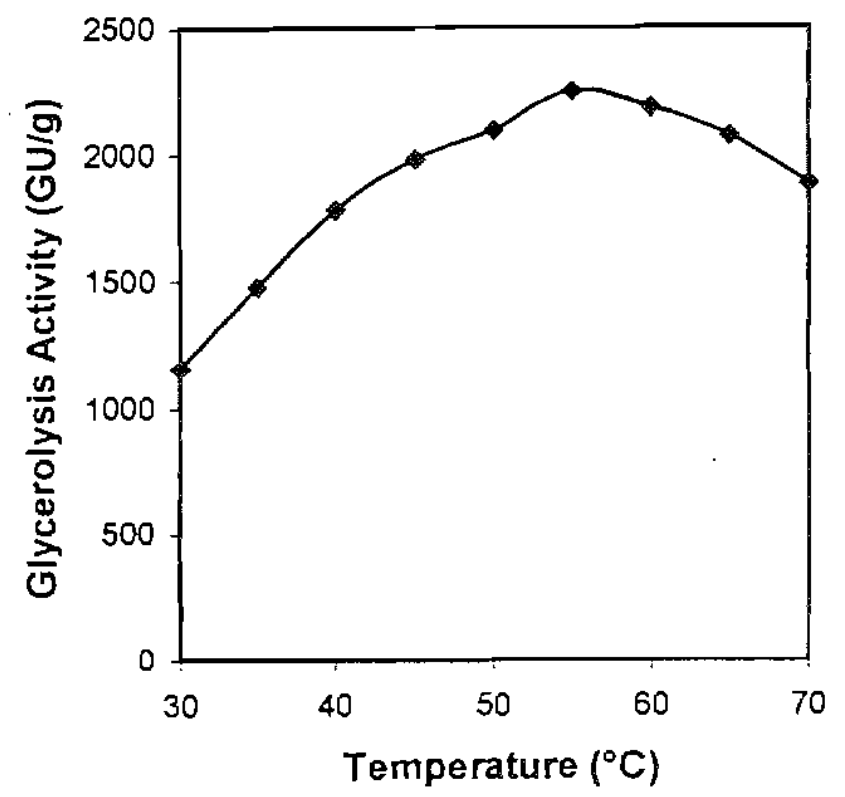

F1G. 4. Activity of Jipase from Pseudomonas sp. as a function of temperature in the glycerolysis of soybean oil at 2:1 molar ratio glycerol/oil and $0.1 \mathrm{~g}$ enzyme/10 $\mathrm{g}$ ail. See Figure 3 for lipase source. 


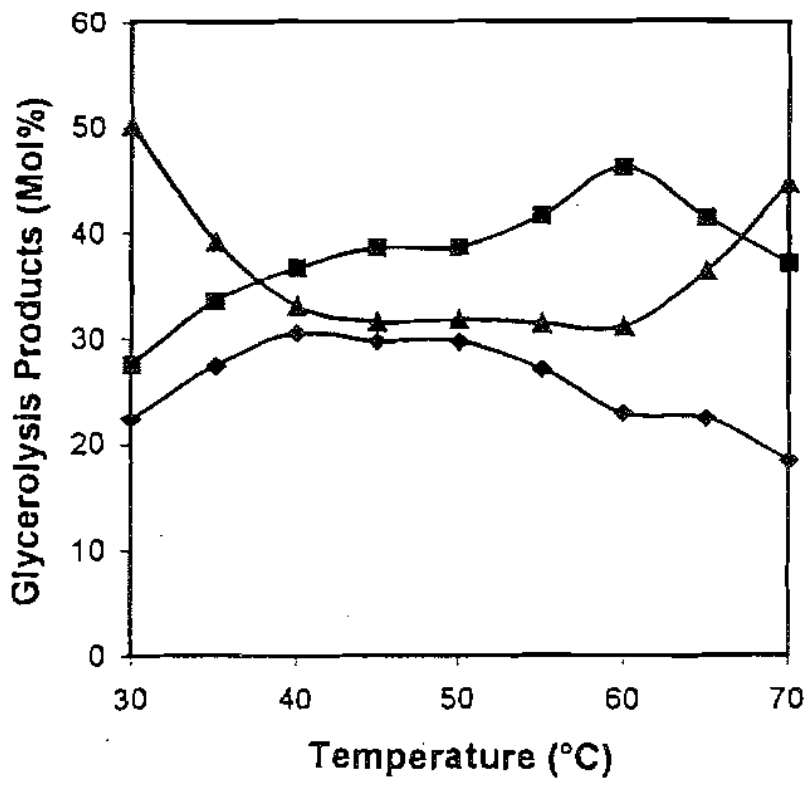

FIG. 5. Effect of temperature on residual activity of lipase PS. Monoglycerides; ( $\mathbf{E}$ ) diglycerides; (A) triglycerides. See Figure 3 for enzyme source.

process temperature must be selected such that the lipase is stable for long periods of time.

The reaction products for which enzyme and oil are incubated at the reaction temperature for $1 \mathrm{~h}$ before glycerol addition are presented in Fig. 5. The dependency of the products on temperature follows a similar trend when compared with normal reactions without the incubation period (Fig. 3). This similarity can also be seen by comparing activities. The glycerolysis activities for the normal and residual activities are presented in Figure 6.

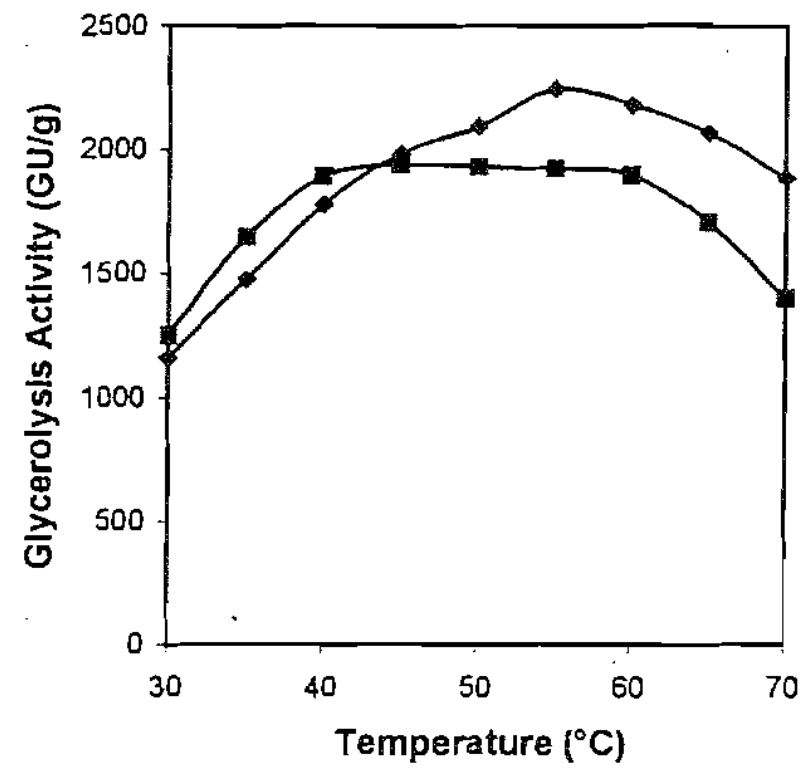

FIG. 6. Glycerolysis activity for normal () and residual (E) activities of lipase PS. See Figure 3 for lipase source.
Examination of Figures 5 and 6 shows a slightly higher enzyme activity below $45^{\circ} \mathrm{C}$ for the residual activity than the normal activity. Prior to the reaction in the residual activity test, the enzyme and oil are incubated at the reaction temperature for $1 \mathrm{~h}$. Therefore, when the glycerol is added, the enzyme is thoroughly steeped with oil and has stabilized at the reaction temperature. In the normal test, the enzyme and oil are only mixed for a few seconds prior to glycerol addition. In addition, it takes some time for the reaction to reach the reaction temperature, since it is placed in the water bath at room temperature. These factors explain why the residual aetivity is higher at lower temperatures. This effect is less pronounced as the temperature increases because of faster heating and increased substrate diffusion during the normal test.

The main distinction between the two experiments is that the maximal activity is seen at a much lower temperature $\left(45^{\circ} \mathrm{C}\right)$ for residual activity experiments compared with the maximal activity without the ineubation period $\left(55^{\circ} \mathrm{C}\right)$. If no enzyme denaturation occurs, the residual activity should be higher than or equal to the normal activity. However, at $45^{\circ} \mathrm{C}$, the residual activity experiments resulted in a lower activity than the normal activity experiments and about equal to the activity at $40^{\circ} \mathrm{C}$. There is a broad maximal range for the residual activity experiments. Apparently, the higher activities and enzyme denaturation at temperatures above $40^{\circ} \mathrm{C}$ result in a relatively constant activity in the $40-60^{\circ} \mathrm{C}$ range. Although slight, enzyme denaturation does begin at $45^{\circ} \mathrm{C}$. This is the intersection of the two activity lines in Figure 6. In developing a continuous process, it is likely that the enzyme cost will be the primary obstacle, making it necessary to sacrifice reaction yield for enzyme stability. Therefore, $40^{\circ} \mathrm{C}$ will be selected as the base temperature for the continuous process.

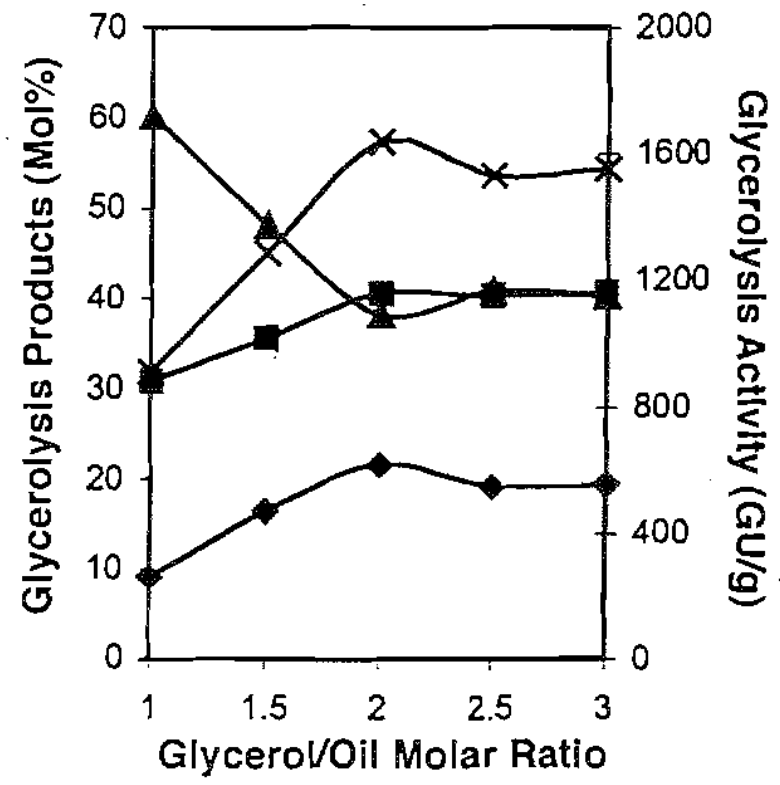

FIG. 7. Effect of glycerol/oil molar ratio on product formation in the glycerolysis of soybean oil at $40^{\circ} \mathrm{C}$ and $0.1 \mathrm{~g}$ lipase PS $10 \mathrm{~g}$ oil. (x) AC-

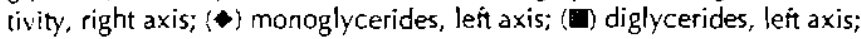
(A) triglycerides, left axis. See Figure 3 for lipase source. 
Glyceroloil ratio. Glycerol/oil molar ratios of 1:1-3:1 were tested. Enzyme loading and reaction temperature were held constant at $0.1 \mathrm{~g}$ enzyme $/ 10 \mathrm{~g}$ oil, and $40^{\circ} \mathrm{C}$, respectively. Reaction results and enzyme activities are presented in Figure 7. MG production increases up to a ratio of 2:1. Above this point a slight decrease is seen followed by no change. This trend is also consistent with the enzyme activity curve. The decrease in reaction yield above 2:1 was unexpected, but can most likely be explained by decreased substrate and product diffusion due to increased viscosity as the glycerol content increases. Therefore, a glycerol/oil molar ratio of $2: 1$ was identified as the most nearly optimal ratio for the reactants.

Enzyme loading. Enzyme/oil ratios of $0.05-0.2 \mathrm{~g}$ enzyme $/ 10 \mathrm{~g}$ oil were tested at a glycerol/oil molar ratio of $2: 1$ and $40^{\circ} \mathrm{C}$ with lipase PS. The reaction results are presented in Figure 8 . Enzyme activities are also presented in this figure. Maximum MG was formed at an enzyme/oil ratio of $0.15 \mathrm{~g}$ enzyme $/ 10 \mathrm{~g}$ oil. However, the difference in MG production over the entire range was small. Maximal giycerolysis activity occurs at a ratio of $0.1 \mathrm{~g}$ enzyme $/ 10 \mathrm{~g}$ oil due to increased $D G$ production at that point. The glycerolysis activity decreases after $0.1 \mathrm{~g}$ enzyme $/ 10 \mathrm{~g}$ oil.

The unexpected decreasing trend in enzyme activity was studied further. An increase in the catalyst loading was expected to have a positive effect on the formation of the product. Under extreme catalyst concentrations, which was well out of the range examined in our experiments, this could have been explained by substrate deficiencies. One possible explanation for the decreased reaction yield may have been insufficient amount of water in the reaction. Lipases require a certain amount of water to function properly. If water is not pre-

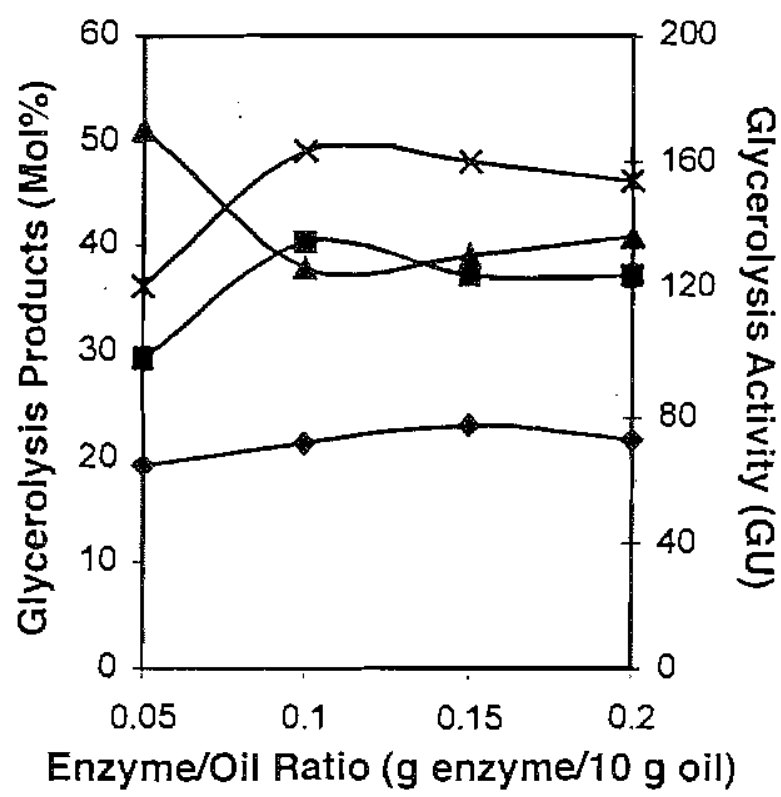

FIG. 8. Effect of lipase PS/oil ratio on product formation in the glyc. erolysis of soybean oil at $40^{\circ} \mathrm{C}$ and a $2: 1$ molar ratio of glycerolioil. ( $x$ ) Activily, right axis; ( ) monoglycerides, left axis; (W) digiycerides, leît axis; (A) triglycerides, left axis. See Figure 3 for enzyme source.
TABLE 3

Effect of Water Content on the Glycerolysis of Soybean Oil with Lipase PS with an Enzyme/Oil Ratio of $0.1 \mathrm{~g} / 10 \mathrm{~g}^{\mathrm{a}}$

\begin{tabular}{lcc}
\hline & $\begin{array}{c}\text { Original water } \\
\text { content }\end{array}$ & $\begin{array}{c}\text { Increased water } \\
\text { content }\end{array}$ \\
\hline Mol/\% MG & 21.7 & 27.8 \\
Mol/\% DG & 37.3 & 40.9 \\
Mol/\% TC & 41.0 & 31.3 \\
Glycerolysis activity (GU/g) & 770.1 & 965.8 \\
\hline
\end{tabular}

${ }^{a}$ For lipase source see Table 1 and for GU definition see Table 2. MG, monoglyceride; DG, diglyceride; TG, triglyceride.

sent, they are unable to assume their functional conformation (17). As the amount of enzyme in the reaction was increased, the amount of water added remained constant. If the amount of water is not enough for the amount of enzyme, the reaction yield will not increase. In fact, the water that is present will be distributed evenly through all enzyme present, resulting in none of the enzyme having enough water to function maximally. This results in a reduction in reaction yield as more enzyme is added.

To test this hypothesis, a reaction with an enzyme/oil ratio of $0.2 \mathrm{~g} / 10 \mathrm{~g}$ was performed with an enzyme/water ratio equal to that which is present at an enzyme/oil ratio of $0.1 \mathrm{~g}$ enzyme/10 g oil. The comparison can be seen in Table 3. As seen here the amount of water in reaction mixture is essential. Therefore, whenever analyzing lipases in glycerolysis reactions the enzyme/water ratio should be maintained constant. Since the eventual goal of this work is a continuous process, it is not necessary to further investigate the enzyme/water relationship, except to verify that such a relationship exists. In a continuous process, glycerol/water will be continuously circulated over the enzyme. Therefore, the en-

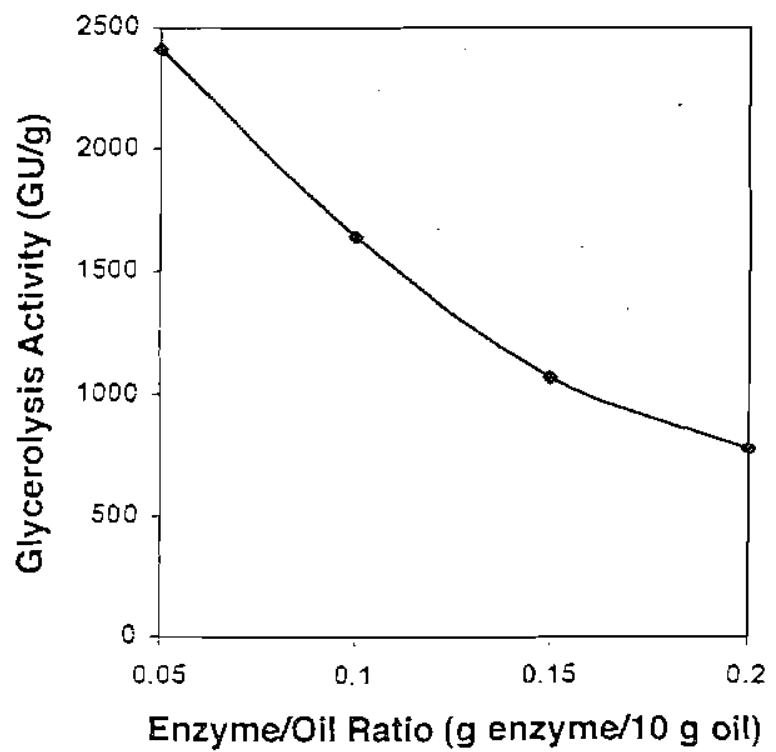

FIG. 9. Efiect of lipase PS/oil ratio in the glycerolysis of soybean oil at $40^{\circ} \mathrm{C}$ and a 2:1 moiar ratio of glyceroloil. See Figure 3 for enzyme source. 
zyme will eventually get all the water it needs, so this effect will only be important during startup.

The glycerolysis activity based on the amount of enzyme in the reaction can be seen in Figure 9. Even in the range when reaction yield increases with increasing enzyme, the activity on a mass basis decreases, indicating little advantage in adding enzyme past a certain point.

The goal of this work was to screen lipases, develop a convenient way to rate those lipases in glycerolysis reactions, and optimize the best-performing lipase in batch setting for the glycerolysis of soybean oil. Since this work is to carry out a preliminary examination of the feasibility of a continuous glycerolysis reaccor, a short reaction time of $1 \mathrm{~h}$ was chosen so that the bases for a direct comparison between batch and continuous reactions could be established. At a $1 \mathrm{~h}$ reaction time, lipase PS showed the most promise.

A convenient definition of glycerolysis activity was used to compare lipases. This concept is important since hydrolysis activity does not reflect glycerolysis activity.

Lipase PS (from Pselidomonas sp.) was further used to optimize reaction parameters in a batch setting. The following conditions were selected to be the basis for a continuous process: $40^{\circ} \mathrm{C}$, a glycerol/oil molar ratio of $2: 1$, and an enzyme/oil ratio of $0.1 \mathrm{~g}$ enzyme/10 g oil.

\section{ACKNOWLEDGMENTS}

The authors express their gratitude to the University of Nebraska Center for Biotechnology and the Department of Chemical Engineering for their suppor of this research.

\section{REFERENCES}

1. Sonntag, N.O.V., Glyceroly sis of Fats and Methyl Esters-Status, Review and Critique, J. Am. Oil Chem. Soc. 59:795A-802A (1982).

2. Rheineck, A.E., R. Bergseth, and B. Sreenivasan, Glycerolysis of Linseed Oil: A Compositional Study, Ibid. 46:447-451 (1968).

3. Birnbaum, H., and J. Lederer, Process for Producing Monoglycerides of Fatty Acids, U.S. Patent 3,102,129 (1963).
4. Noureddini, H., and V. Medikonduru, Glycerolysis of Fats and Merhyl Esters, J. Am. Oil Chem. Soc. 74:419-425 (1997).

5. Masuyama, S., M. Takasago, K. Horikawa, F. Fujiwara, and C. Sugimoto, Glycerolysis of Fatty Acid Methyl Esters. II. Synthesis of Pure 1-Monopalmitin, Kagaku to Kogyo (Osaka) 42:242-248 (1968).

6. Takeda, Y., R. Yasue, and Y. Miyawaki, Preparation of Monoglycerides by Two-Step Reaction, Japanese Patent 1,268.663 (1989).

7. Potts, R.H., and V.J. Muckerheide, Production of Fatty Acids, in Fatty Acids and Their Industrial Applications, edited by E.S. Partison, Marcel Dekker Inc., New York, 1968, pp. 21-46.

8. McNeill, G.P., and T. Yamane, Further Improvements in the Yield of Monoglycerides During Enzymatic Glycerolysis of Fats and Oils. J. Am. Oil Chem. Soc. 68:6-10 (1991).

9. McNeil, G.P.. S. Shimizu, and T. Yamane, High-Yield Enzymatic Glycerolysis of Fats and Oils, lbid. 68:1-5 (1991).

10. Cao, S.G., X.G. Gao, and K.E. Zhang, Enzymatic Preparation of Monoglycerides via Glycerolysis of Fats and Oils Catalyzed by Lipase from Pseudomonas Species, Amn. N.Y. Acad. Sci. 799:670-677 (1996).

11. Holmberg, K., B. Lassen, and M.B. Stark, Enzymatic Preparation of Monoglycerides in Microemulsion, J. Am. Oil Chem. Soc. 66:1796-1800 (1989).

12. Hoq, M.M., T. Yamane, S. Shimizu, T. Funada, and S. Ishida, Continuous Synthesis of Glycerides by Lipase in a Microporous Membrane Bioreacior, lbid. 61:776-781 (1984).

13. Daeseok. H.. and J. S. Rhee, Characteristics of Lipase-Catalyzed Hydrolysis of Olive Oil in AOT-Isooctane Reversed Micelles, Biotechnol. Bioeng. 28:1250-1255 (1986).

14. International Union of Biochemistry and Molecular Biology Nomenclature Committee, Enzyme Nomenclarture, New York, Academic Press, 1992.

15. Chang, P.S., and J.S. Rhee, Continuous Glycerolysis of Olive Oil by Chromobacteriun visiosum Lipase Immobilized on Liposome in Reversed Micelles, Bioiech. Bioeng. 38:1159-1165 (1991).

16. Yang, B., W.J. Harper, and K.L. Parkin, Control of Lipase-Mediated Glycerolysis Reactions with Butteroil in Dual Liquid Phase Media Devoid of Organic Solvent, J. Agric. Food Chem. 4l:1905-1909 (1993).

17. Yang, B., and K.L. Parkin, Monoacyl Prodution from Butteroil by Glycerolysis with a Gel-Entrapped Microbial Lipase in Microaqueous Media, J. Food Sci. 59:47-52 (1994).

[Received April 27, 1998; accepted June 15, 1998] 